九州大学学術情報リポジトリ

Kyushu University Institutional Repository

非観血式血圧測定方式（直線加圧方式と減圧方式） の違いによるパルスオキシメーターアラーム発生頻 度の比較

北本，憲永

ht tps://doi. org/10.15017/4060094

出版情報：Kyushu University，2019，博士（学術）， 課程博士 バージョン：

権利関係 : 


\section{The measurement of blood pressure by the linear method compared to the deflation methods differently modifies the pulse oximeter alarm frequency Norihisa Kitamoto a,b , Takashi Hitosugi ${ }^{a}$, Yoshifumi Kawakubo ${ }^{a}$, Keisuke Hayashi ${ }^{a}$ and Takeshi Yokoyama ${ }^{a}$}

\begin{abstract}
Background Noninvasive blood-pressure measurement device and pulse oximeter are important for patient monitoring. When these are placed on the same side, cuff inflation sometimes causes measurement failure by pulse oximeter.
\end{abstract}

\begin{abstract}
Objective The present study aimed to compare the pulse oximeter alarm frequency and pulse-wave disappearance duration between noninvasive bloodpressure measurement using the deflation method and that using the linear inflation method.
\end{abstract}

Methods The study included 10 healthy subjects. The cuff for automatic sphygmomanometer was wrapped on one side of the upper arm and for pulse oximeter was attached to the thumb of the same side of upper limbs.

Results The alarm frequency was 0 and $26 \%$ using the linear inflation and the deflation methods, respectively. Additionally, the pulse-wave disappearance duration was significantly longer using the deflation method than that using the linear inflation method ( $10.0 \pm 1.5$ vs $1.7 \pm 0.8 \mathrm{~s})$. With the linear inflation method, this duration was or less $3 \mathrm{~s}$. In the deflation method, an excess pressure of $40 \mathrm{mmHg}$ was used, which caused the alarm to turn on. Additionally,

\section{Introduction}

During treatment and examinations in clinical settings as the intensive care, operating, and catheter rooms, it is important to continuously monitor patients using instruments, such as electrocardiogram, noninvasive blood-pressure monitor, and percutaneous arterial blood oxygen saturation $\left(\mathrm{SpO}_{2}\right)$ monitor (pulse oximeter), and to respond instantly to any change in their condition. Usually, blood pressure is noninvasively measured using an oscillometric automated blood-pressure monitor (automatic sphygmomanometer) by wrapping its cuff around the upper arm. $\mathrm{SpO}_{2}$ is measured by attaching a pulse oximeter on a finger on the contralateral side to prevent the occurrence of a situation where $\mathrm{SpO}$, becomes unmeasurable. However, in certain cases such as after upper limb surgery, breast surgery, and examination or treatment in catheter rooms, the pulse oximeter may be placed on a finger of the same limb to which with the cuff is attached. In the step deflation method, the conventional blood-pressure measurement method, a constant the heart rate was found to influence the alarm occurrence during measurement using the deflation method.

Conclusion Heart rate may influence alarm occurrence during blood-pressure measurement using the step deflation method. Using the linear inflation method, the risks of alarm occurrence and measurement failure are low, even when the pulse oximeter and blood-pressure measurement cuffs are installed on the same side, suggesting that this method is suitable for clinical use. Blood Press Monit XXX:000-000 Copyright (c) 2019 Wolters Kluwer Health, Inc. All rights reserved.Blood Pressure Monitoring 2019, XXX:000-000

Keywords: blood pressure, deflation method, heart rate, linear inflation method, noninvasive blood-pressure measurement device, pulse oximeter

${ }^{a}$ Department of Dental Anesthesiology, Faculty of Dental Science, Kyushu University, Fukuoka and ${ }^{b}$ Seirei hamamatsu General Hospital Department of Clinical Engineering, Hamamatsu, Japan

Correspondence to Takashi Hitosugi, DMD, PhD, Department of Dental Anesthesiology, Faculty of Dental Science, Kyushu University, 3-1-1 Maidashi, Higashi-ku, Fukuoka 812-8582, Japan

Tel: +8192 642 6480; fax: +8192642 6481;

e-mail: hitosugi.takashi.724@m.kyushu-u.ac.jp

Received 13 May 2019 Accepted 13 September 2019

pressure is applied and measurement is performed while reducing the applied pressure. For accurate assessment, pressurization above the systolic blood pressure is necessary. Therefore, pulse oximeter cannot perform measurements [1-4] every time a pulse occurs during such assessments, and the pulse-wave disappearance alarm is sometimes triggered. In addition, in the actual analysis of alarms using biological information monitors, pulse oximeter alarms have been reported as the most frequent arrhythmia-indicating alarms [5]. The occurrence of such alarms can result in problems with patient safety management, patient anxiety, and increased staff work volume.

Recently, an automatic sphygmomanometer involving a linear inflation method for blood-pressure measurement was developed, and its measurement precision, ability to reduce the measurement time, usefulness for preventing overpressurization have been reported [6-8]. However, no previous study has investigated the alarm frequency associated with pulse-wave disappearance during noninvasive blood-pressure measurement using an automatic 
sphygmomanometer when the pulse oximeter is used on the side with the cuff.

\section{Methods}

\section{Sample, setting, and interventions}

The study enrolled 10 healthy volunteers who provided consent and who were informed regarding the research aims. The automatic sphygmomanometer used was the BSN-1763 multimonitor (Nihon Koden Co., Ltd., Tokyo, Japan) with a linear inflation function, step deflation function, and pulse oximeter. The measurement response of the pulse oximeter was set to the 'fast' mode.

The volunteers were placed in a resting state. The same examiner cuffed the upper arm of all volunteers, and a pulse oximeter was attached to the thumb on the same side. Measurements were performed in the supine position. Measurements were performed using linear inflation and deflation methods four times for each volunteer. In the deflation method, except for the initial overpressure, data of the second and subsequent three measurements were evaluated. Similarly, in the linear inflation method, data of the second and subsequent three measurements were evaluated. Heart rate, systolic blood pressure, diastolic blood pressure, pulse oximeter value, alarm frequency, and pulse-wave disappearance duration were compared between the linear inflation and deflation methods. The pulse-wave disappearance time was defined as the time from pulse disappearance associated with pressurization to pulse reappearance after the release of cuff pressure and resumption of blood flow. This study was conducted on 30 March 2016, with approval from the 306th Seireihamamatsu Hospital Clinical Research Review Committee (receipt number 2058).

\section{Statistical analysis}

Numerical data are presented as mean \pm SD. The Student's $t$-test was used for all statistical analyses. A $P$ value of $<0.05$ was considered as statistically significant.

\section{Results}

The mean age of the volunteers was $33.7 \pm 6.7$ years, male:female ratio was $6: 4$, mean height was $167.5 \pm 10.3 \mathrm{~cm}$, and mean body weight was $59.9 \pm 12.8$. There were no significant differences with regard to heart rate, noninvasive blood-pressure values, and pulse oximeter values between the linear inflation and deflation methods (Table 1). The alarm frequency was 0 and

Table 1 Measurement date

\begin{tabular}{lccc}
\hline Characteristic & Liner inflation method & Deflation method & $P$ value \\
\hline Heart rate & $76.2 \pm 13.7$ & $75.5 \pm 15.2$ & 0.796 \\
Systolic BP $(\mathrm{mmHg})$ & $118.1 \pm 8.7$ & $117.5 \pm 9.8$ & 0.824 \\
Diastolic BP $(\mathrm{mmHg})$ & $76.2 \pm 10.0$ & $76.9 \pm 10.1$ & 0.798 \\
Pulse pressure $(\mathrm{mmHg})$ & $41.8 \pm 9.5$ & $40.6 \pm 10.5$ & 0.645 \\
$\mathrm{SpO}_{2}(\%)$ & $98.1 \pm 1.2$ & $98.3 \pm 1.1$ & 0.576 \\
\hline
\end{tabular}

$\mathrm{BP}$, blood pressure; $\mathrm{SpO}_{2}$, percutaneous arterial blood oxygen saturation.
$26 \%$ using the linear inflation and deflation methods, respectively. The pulse-wave disappearance duration was significantly longer using the deflation method than that using the linear inflation method $(10.0 \pm 1.5 \mathrm{vs} 1.7 \pm 0.8 \mathrm{~s}$, $P<0.001$ ) (Table 2). Using the deflation method, heart rate was found to be significantly lower in cases of alarm occurrence than that in cases without alarm occurrence $(67.3 \pm 13.5$ vs $78.5 \pm 15.0, P=0.03)$. Additionally, using the deflation method, pulse-wave disappearance duration was significantly higher in cases with alarm occurrence than that in cases without alarm occurrence $(11.0 \pm 1.4 \mathrm{vs}$ $9.7 \pm 1.6 \mathrm{~s}, P=0.004)$ (Table 3).

\section{Discussion}

In this study, we assessed the alarm frequency and the pulse-wave disappearance duration using the linear inflation and the deflation methods. During blood-pressure measurement, cuff pressure was increased to a level at which the pulse wave could not be detected. Using the linear inflation method, the pulse-wave disappearance durations were all within $3 \mathrm{~s}$. As the measurement response of the pulse oximeter was set to 'fast,' the multimonitor used for assessment detected the pulse wave and provided the average value of $4 \mathrm{~s}$ (the device has 'fast', 'normal', and 'slow' modes and the average durations are 4,8 , and $16 \mathrm{~s}$, respectively). Furthermore, according to the algorithm, the time to preserve the value was set to $8 \mathrm{~s}$ when the pulse wave could not be detected. Additionally, within the duration of aforementioned value preservation, the system was set to temporarily prevent a false alarm even if the waveform was not detected owing to noise or body movement. Therefore, if the pulse-wave disappearance duration is within approximately $3 \mathrm{~s}$, the pulse-wave undetected alarm will not occur. Consistent with this, the linear inflation method displayed values without alarm occurrence. Conversely, in the deflation method, a $+40 \mathrm{mmHg}$ pressure is applied the systolic pressure, which is determined from the previous measurement. Thus, additional time is required for excessive

Table 2 Alarm frequency and pulse-wave disappearance time

\begin{tabular}{lccc}
\hline Variable & $\begin{array}{c}\text { Liner } \\
\text { inflation method }\end{array}$ & $\begin{array}{c}\text { Deflation } \\
\text { method }\end{array}$ & $P$ value \\
\hline Alarm frequency (\%) & 0 & 26.6 & $<0.001$ \\
Pulse wave disappearance time (s) & $1.7 \pm 0.8$ & $10.0 \pm 1.5$ & $<0.001$ \\
Max time (s) & 3.6 & 13.9 & \\
Min time (s) & 0.6 & 7.6 & \\
\hline
\end{tabular}

Table 3 Measurement date for alarm and no-alarm subgroups using the deflation method

\begin{tabular}{lccc}
\hline Variable & Alarm & No alarm & $P$ value \\
\hline Heart rate & $67.3 \pm 13.5$ & $78.5 \pm 15$ & $0.035^{*}$ \\
Systolic BP $(\mathrm{mmHg})$ & $117.0 \pm 3.1$ & $117.7 \pm 11.3$ & 0.786 \\
Diastolic BP $(\mathrm{mmHg})$ & $80.4 \pm 8.8$ & $75.6 \pm 10.5$ & 0.223 \\
Pulse pressure $(\mathrm{mmHg})$ & $36.6 \pm 7.9$ & $42.1 \pm 11.1$ & 0.155 \\
Pulse-wave disappearance time (s) & $11.0 \pm 1.4$ & $9.7 \pm 1.6$ & $0.004^{*}$ \\
\hline
\end{tabular}

$\mathrm{BP}$, blood pressure. 
pressurization and pulse-wave detection at the systolic pressure (Fig. 1). An alarm occurs when the whole pulse duration is $10 \mathrm{~s}$ and the pulse-wave disappearance duration is approximately $11 \mathrm{~s}$. As significant differences were noted in heart rate and pulse-wave disappearance duration between cases of alarm occurrence and those without alarm occurrence using the deflation method, Nihon Koden, Co., Ltd. was requested to investigate the algorithm for blood-pressure measurement. Eventually, it was confirmed that heart rate was affecting the measurement speed in the deflation method. When the systolic pressure was noted during measurements using the step deflation method, the pressure was decreased for three steps after sensing two heartbeats; from the fourth step onward, the pressure was reduced at every heartbeat. Therefore, the alarm subgroup had a slow heart rate that caused the deflation rate to decrease and the time for pulse-wave detection to increase. In patients with higher blood pressure, we expect that the linear inflation methods have little influence on the pulse oximeter alarm. But, deflation methods, especially in a slow heart rate, have a great influence on that. In addition, the pressure was reduced by $10 \mathrm{mmHg}$ for every step when the pressure was $\geq 100 \mathrm{mmHg}$ and by $8 \mathrm{mmHg}$ when the pressure was $<100 \mathrm{mmHg}$. These findings indicate that it takes time to measure low blood pressure, possibly leading to alarm occurrence. In this investigation, we believe that the relationship between the pulse-wave disappearance duration and the pulse-wave recognition function was influenced, which was inferred from the fact at in one case, alarm occurrence was not noted at $11 \mathrm{~s}$ (Fig. 2). Characteristics of the oscillometric method are thought to influence the pulse-wave recognition function. To calculate the systolic pressure after detecting the pulse wave, the oscillometric method uses a value of approximately $40 \%$ of the maximum amplitude at the mean blood pressure as the systolic ratio [9-11]. The findings might be associated with the systolic ratio and the properties of the blood vessels of the assessed individuals.

Setting the pulse-wave averaging time to 'slow' before alarm occurrence using the deflation method can reduce the alarm frequency and the value holding time in addition to the value averaging time. However, when the pulse wave disappears owing to an increase in cuff pressure, there is a shift to the holding time from the undetectable time, and when it exceeds the value holding time, a pulse-wave undetected alarm is triggered. Therefore, it was confirmed from the algorithm that the extension of the pulse wave does not prevent alarm occurrence. Considering pulse oximeter alarm characteristics, the pulse oximeter response can be increased using the 'fast' mode, and the numerical change can be accurately displayed [12]. Additionally, using the linear inflation method, the unmeasurable duration and alarm frequency can be reduced. Alarm frequency needs to be reduced as much as possible in order to reduce issues with patient safety management and the stress of medical staff, such as operators [4].

Fig. 1

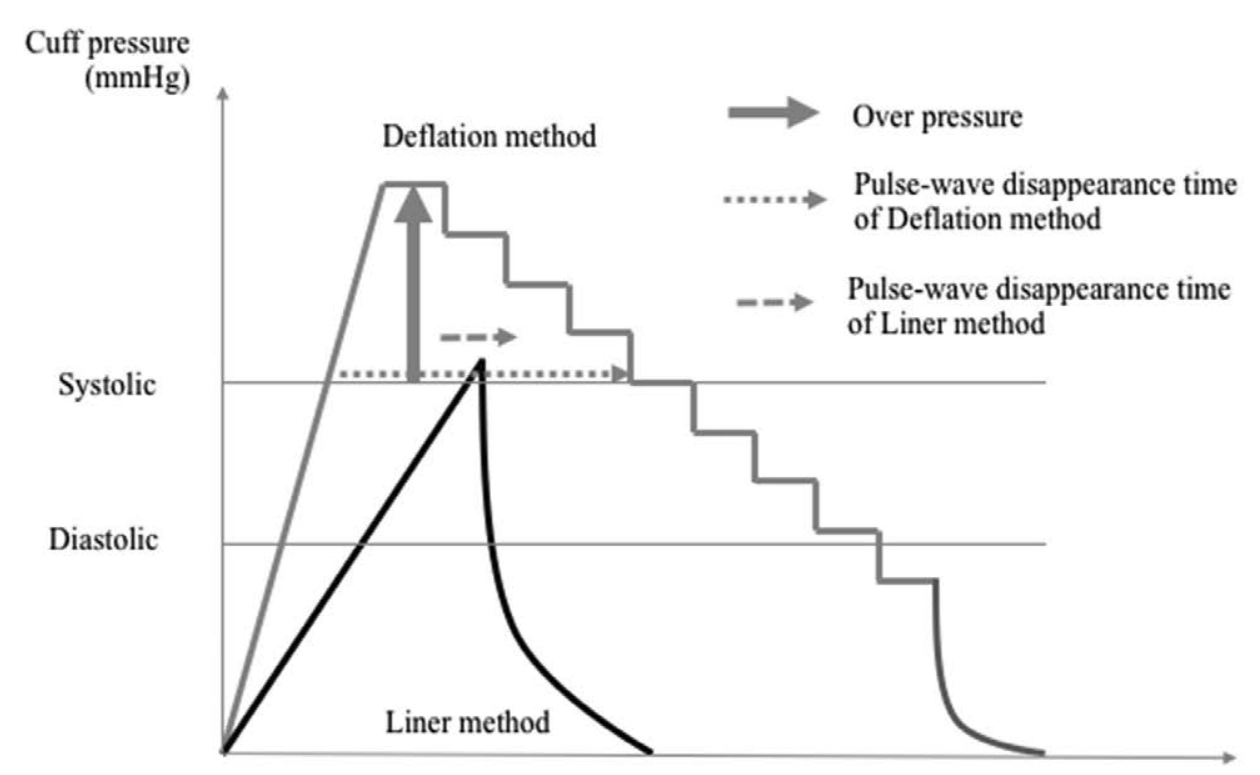

Time

Causes of difference in pulse-wave disappearance time between linear pressure method and deflation method. At the same time as the linear method reaches the systolic blood pressure, the pressurization is terminated. On the other hand, in the deflation method, a $+40 \mathrm{mmHg}$ pressure is applied the systolic pressure, which is determined from the previous measurement. Thus, additional time is required for excessive pressurization and pulse-wave detection at the systolic pressure. 


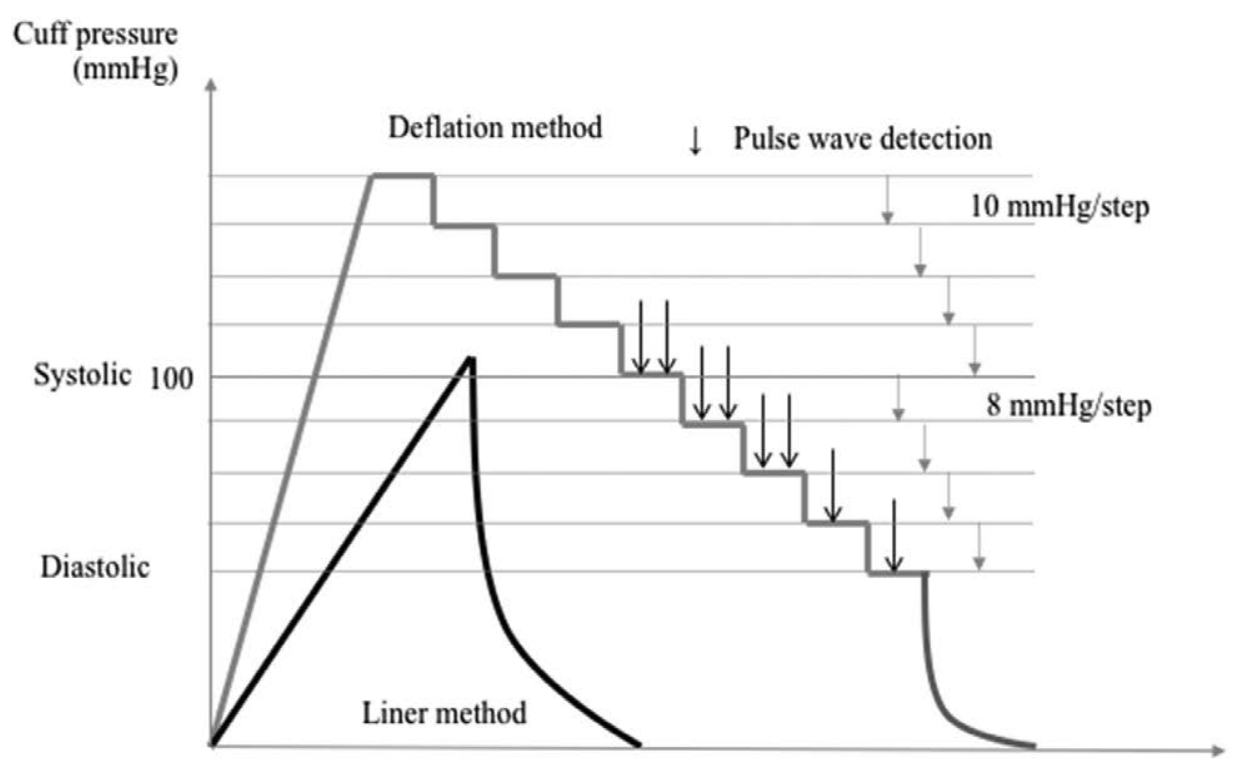

Time

The relationship between the deflation method and heart rate. It was confirmed that heart rate was affecting the measurement speed in the deflation method. When the systolic pressure was noted during measurements using the deflation method, the pressure was decreased for three steps after sensing two heartbeats; from the fourth step onward, the pressure was reduced at every heartbeat. Therefore, the alarm subgroup had a slow heart rate that caused the deflation rate to decrease and the time for pulse-wave detection to increase. In addition, the pressure was reduced by $10 \mathrm{mmHg}$ for every step when the pressure was $\geq 100 \mathrm{mmHg}$ and by $8 \mathrm{mmHg}$ when the pressure was $<100 \mathrm{mmHg}$. These findings indicate that it takes time to measure low blood pressure, possibly leading to alarm occurrence.

In this study, we noted fluctuations in the blood-pressure value within a range that did not exceed the previous value of $+40 \mathrm{mmHg}$ using the deflation method. In clinically invasive cases, vasoactive drugs, catecholamines, and other drugs may cause a rapid increase in blood pressure. In such cases, blood-pressure fluctuations may be $\geq 40 \mathrm{mmHg}$ of the previous value. In these cases, automatic sphygmomanometers require multiple inflations using the deflation method, increasing the pulse-wave disappearance duration and alarm frequency. Additional consideration is required on how to slow the deflation speed in patients with low blood pressure and how the change in heart rate affects the alarm frequency.

As this study included only healthy subjects, additional evaluations are required in clinical patients, such as children with a high heart rate and elderly patients. These individuals may have conditions, such as peripheral circulation dynamic failure, that can affect pulse-wave detection. In addition, the same automatic sphygmomanometer model was used for all evaluations in this study. Thus, we could not compare different automatic sphygmomanometer models from different companies. Thus, further studies considering these aspects are warranted.

\section{Conclusion}

For blood-pressure measurement using the linear inflation method, the risks of alarm occurrence and measurement failure are low, even when the pulse oximeter and sphygmomanometer cuff are placed on the same side, suggesting that this method is suitable for clinical use. Conversely, using the step deflation method, the risks of alarm occurrence and measurement failure are high, and the pulse-wave disappearance time and heart rate can influence alarm occurrence.

\section{Acknowledgements}

The work was supported by Seirei Hamamatu General Hospital that equipment for blood-pressure measurements using the linear inflation method was borrowed.

All procedures performed in studies involving human participants were in accordance with the ethical standards of the institutional and/or national research committee and with the 1964 Helsinki declaration and its later amendments or comparable ethical standards.

Informed consent was obtained from all individual participants included in the study.

\section{Conflicts of interest}

There are no conflicts of interest.

\section{References}

1 Mendelson Y. Pulse oximetry: theory and applications for noninvasive monitoring. Clin Chem 1992; 38:1601-1607. 
2 Weiss BM, Pasch T. Measurement of systemic arterial pressure. Curr Opin Anaesthesiol 1997; 10:459-466.

3 Sinex JE. Pulse oximetry: principles and limitations. Am J Emerg Med 1999; 17:59-67.

4 DeMeulenaere S. Pulse oximetry: uses and limitations. J Nurse Pract 2007; 3:312-317.

5 Lansdowne K, Strauss DG, Scully CG. Retrospective analysis of pulse oximeter alarm settings in an intensive care unit patient population. BMC Nurs 2016; 15:36.

6 Onodera J, Kotake Y, Fukuda M, Yasumura R, Oda F, Sato N, et al. Validation of inflationary non-invasive blood pressure monitoring in adult surgical patients. J Anesth 2011; 25:127-130.

7 Sasaki J, Kikuchi Y, Usuda T, Hori S. Validation of inflationary noninvasive blood pressure monitoring in the emergency room. Blood Press Monit 2015; 20:325-329.
8 Zheng D, Pan F, Murray A. In response: confirmation of the need to evaluate devices that measure bloodpressure during cuff inflation with manual measurements during normal deflation. Blood Press Monit 2013; 18:265-271.

9 Drzewiecki G, Hood R, Apple H. Theory of the oscillometric maximum and the systolic and diastolic detection ratios. Ann Biomed Eng 1994; 22:88-96.

10 Forster FK, Turney D. Oscillometric determination of diastolic, mean and systolic blood pressure-a numerical model. J Biomech Eng 1986; 108:359-364.

$11 \mathrm{Ng} \mathrm{KG}$, Small CF. Changes in oscillometric pulse amplitude envelope with cuff size: implications for blood pressure measurement criteria and cuff size selection. J Biomed Eng 1993; 15:279-282.

12 International Organization for Standard. ISO9919, Medical electrical equipment - Particular requirements for the basic safety and essential performance of pulse oximeter equipment for medical use. Second edition. Geneva: International Organization for Standard; 2005. 